\title{
Corrigendum: Modeling habits as self-sustaining patterns of sensorimotor behavior
}

\author{
Matthew D. Egbert ${ }^{1 *}$ and Xabier E. Barandiaran ${ }^{2,3}$ \\ ${ }^{1}$ Embodied Emotion, Cognition and (Inter) Action Lab, School of Computer Science, University of Hertfordshire, Hatfield, UK, \\ ${ }^{2}$ Department of Philosophy, University School of Social Work, UPV/EHU, University of the Basque Country, Spain, \\ ${ }^{3}$ IAS-Research Center for Life, Mind, and Society, UPV/EHU University of the Basque Country, Spain
}

Keywords: sensorimotor, self-maintaining patterns-of-behavior, mental-life, habits, meso-scale modeling

\section{A corrigendum on}

Modeling habits as self-sustaining patterns of sensorimotor behavior by Egbert, M. D., and Barandiaran, X. E.(2014) Front. Hum. Neurosci. 8:590. doi: 10.3389/fnhum. 2014.00590

In this article, Equation 8 is incorrectly written:

$$
\Gamma\left(a, N_{v}\right)=a-a \cdot \frac{N_{v}}{\left\|N_{v}\right\|},
$$

The correct equation is:

$$
\Gamma\left(a, N_{v}\right)=a-\left(a \cdot \frac{N_{v}}{\left\|N_{v}\right\|}\right) \frac{N_{v}}{\left\|N_{v}\right\|},
$$

where the right-hand-side of the equation represents the vector $a$ with its component parallel to $N_{v}$ removed.

In the paper, this function is used to calculate the "attraction" influence of nodes. The vector $a$ is the difference between the node's position $\left(N_{p}\right)$ and the current sensorimotor state $(x)$, and $\Gamma$ removes the component of $a$ that is parallel to $N_{v}$.

All of the simulations presented in the original paper were performed with the correct evaluation of $\Gamma\left(a, N_{v}\right)$. This was only a typo in the manuscript.

\section{OPEN ACCESS}

Edited and reviewed by: Javier Bernacer,

University of Navarra, Spain

*Correspondence: Matthew D. Egbert, mde@matthewegbert.com

Received: 11 March 2015 Accepted: 30 March 2015

Published: 20 April 2015

Citation:

Egbert MD and Barandiaran XE (2015)

Corrigendum: Modeling habits as

self-sustaining patterns of

sensorimotor behavior.

Front. Hum. Neurosci. 9:209.

doi: 10.3389/fnhum.2015.00209

\section{Acknowledgments}

Matthew Egbert's contributions to this research were funded by the European Commission as part of the ALIZ-E project (FP7-ICT-248116). Xabier Barandiaran's work was funded by the eSMCs: Extending Sensorimotor Contingencies to Cognition project, FP7-ICT-2009-6 no: IST-270212. Research project "Autonomia y Niveles de Organizacion" financed by the Spanish Government (ref. FFI2011-25665) and IAS-Research group funding IT590-13 from the Basque Government. The authors would also like to thank Eran Agmon as well as Lola Cañamero and the other members of the Embodied Emotion, Cognition and (Inter-)Action Lab for discussions of the research presented above. The opinions expressed are solely the authors.

Conflict of Interest Statement: The authors declare that the research was conducted in the absence of any commercial or financial relationships that could be construed as a potential conflict of interest.

Copyright () 2015 Egbert and Barandiaran. This is an open-access article distributed under the terms of the Creative Commons Attribution License (CC BY). The use, distribution or reproduction in other forums is permitted, provided the original author(s) or licensor are credited and that the original publication in this journal is cited, in accordance with accepted academic practice. No use, distribution or reproduction is permitted which does not comply with these terms. 